\title{
Des-Gamma-Carboxy Prothrombin (DCP) Antagonizes the Effects of Gefitinib on Human Hepatocellular Carcinoma Cells
}

\author{
Yu-Sheng Zhang ${ }^{\mathrm{a}} \quad$ Jia-Hui Chu ${ }^{\mathrm{a}}$ Zhi-Yu Song ${ }^{\mathrm{a}}$ Shu-Xiang Cuib Xian-Jun Qu \\ aSchool of Pharmaceutical Sciences, Shandong University, Jinan, ${ }^{b}$ Evaluation Center for Food and Drug, \\ Capital Medical University, Beijing, China
}

\section{Key Words}

Human hepatocellular carcinoma cells (HCC) • Gefitinib • Chemotherapy • Apoptosis resistance - Des-gamma-carboxy prothrombin (DCP) - Antagonistic effect

\begin{abstract}
Background/Aims: Des-gamma-carboxy prothrombin (DCP), an aberrant prothrombin produced by hepatocellular carcinoma (HCC) cells, is known as a marker for HCC. Recent studies indicated that high levels of DCP are associated with the malignant potential of HCC. In this study, we aimed to investigate the association of DCP with gefitinib treatment failure in HCC and whether DCP counteracts gefitinib-induced growth inhibition and apoptosis of HCC. Methods: The experiments were performed in HCC cell lines HepG2 and PLC/PRF/5. The effects of gefitinib on HCC in the presence or absence of DCP were evaluated by the 3-[4, 5-dimethylthiazol-2-yl]-2, 5-diphenyl-tetrazolium bromide (MTT) assay. Apoptotic cells were identified by Annexin V-FITC/PI staining. Western blotting was performed to analyze the expressions of molecules related to the apoptotic caspase-dependent pathway and epidermal growth factor receptor (EGFR) pathway. Results: Gefitinib inhibited HCC cell proliferation and induced apoptosis in HCC cells. The effects of gefitinib on HCC cells were antagonized by DCP. In the presence of DCP, HCC cells were resistant to the gefitinib-induced inhibition of proliferation and stimulation of apoptosis. DCP prevented the activation of the apoptotic caspase-dependent pathway induced by gefitinib. These antagonistic effects of DCP also arose from its ability to up-regulate EGFR, c-Met and hepatocyte growth factor (HGF) in HCC cells. Conclusion: DCP antagonized gefitinib-induced HCC cell growth inhibition by counteracting apoptosis and up-regulating the EGFR pathway. High levels of DCP might thus lead to low response rates or possibly no response to gefitinib in patients with HCC.
\end{abstract}

Professor Xian-Jun Qu

KARGER 125 


\section{Introduction}

Hepatocellular carcinoma (HCC) is the most common primary liver malignancy worldwide and is the second most frequent cause of cancer death in men [1]. HCC can be treated by resection, liver transplantation and radiofrequency ablation for patients diagnosed at an early stage [2]. However, most patients with HCC are diagnosed at an advanced stage or progress after successful initial treatment [3]. Among those patients whose tumor characteristics are not appropriate for surgical therapy or those with tumor recurrence, systemic chemotherapy has still been considered as a strategy for improving survival. Systemic therapies examined in the past, mainly the cytotoxic agents, have provided limited benefits for patients with HCC [2].

Gefitinib is a tyrosine kinase inhibitor that has been considered to have survival benefits for HCC patients [4]. Gefitinib mainly targets the epidermal growth factor receptor (EGFR) through the suppression of tyrosine kinase activity [5]. Gefitinib was also found to exert its activity through the inhibition of c-Met and hepatocyte growth factor (HGF), among its other cellular functions [6]. However, the response to gefitinib treatment is quite different for different patients with HCC. In fact, most, if not all, patients derived limited benefits and had low response rates to gefitinib [7]. Some patients, who initially respond to gefitinib, subsequently become refractory, and after a few months of therapy, develop tumor progression. These clinical symptoms indicated the development of gefitinib resistance [7]. Although several mechanisms have been suggested, such as cross-talk between the phosphatidylinositol 3-kinase (PI3K)/Akt and JAK-STAT (Janus family tyrosine kinases (Jak kinases) pathways and signal transducers and activators of transcription (STAT proteins) [7], the exact mechanism leading to the production of gefitinib-resistant cells is still far from being defined. In this study, we demonstrated that des- $\gamma$-carboxyl prothrombin (DCP) produced in HCC, might be one of the reasons for the limited efficacy of gefitinib in HCC, leading to gefitinib treatment failure. DCP was found to antagonize the inhibitory effect of gefitinib on HCC. In the presence of DCP, HCC resisted gefitinib-induced apoptosis. These results suggested that DCP production might play a key role in the failure of gefitinib treatment in HCC.

\section{Materials and Methods}

\section{DCP and gefitinib}

Des-gamma-carboxy prothrombin (DCP) was a gift from Eisai Co., Ltd., Japan. DCP was purified from the conditioned media of DCP-producing cell lines by affinity chromatography with an anti-prothrombin antibody [8]. Gefitinib was kindly provided by AstraZeneca, London, UK. Gefitinib was dissolved in dimethylsulfoxide (DMSO, Sigma-Aldrich) at $20 \mathrm{mM}$ as a stock solution before use.

\section{Cell Lines and cell culture}

Human HCC cell lines, PLC/PRF/5 and HepG2, were purchased from the American Type Culture Collection (Manassas, USA). HCC cells were maintained in RPMI- 1640 supplemented with $10 \%$ (v/v) heatinactivated fetal bovine serum, $2 \mathrm{mM}$ glutamine, and $10 \mathrm{mM}$ Hepes buffer at $37^{\circ} \mathrm{C}$ in a humid atmosphere $\left(5 \% \mathrm{CO}_{2}-95 \%\right.$ air) and were harvested by brief incubation in $0.02 \%$ EDTA-PBS.

\section{3-(4, 5-dimethylthiazol-2-yl)-2, 5-diphenyltetrazolium bromide (MTT) assay}

HCC cells were seeded in 96 -well plates $\left(3 \times 10^{3}\right.$ per well) and exposed to various concentrations of gefitinib, DCP or gefitinib plus DCP for $72 \mathrm{~h}$. Then, the medium was removed and the wells were washed with PBS. Cell viability was estimated by the 3-(4,5-dimethylthiazol-2-yl)-2, 5-diphenyltetrazolium bromide (MTT) assay after adding $20 \mu \mathrm{l}$ of MTT ( $5 \mathrm{mg} / \mathrm{ml}$, Sigma-Aldrich) for $4 \mathrm{~h}$. Light absorbance of the solution was measured at $570 \mathrm{~nm}$ on a microplate reader (Perkin-Elmer, USA). The growth of experimental and control cells was compared. Each treatment with gefitinib, DCP or gefitinib plus DCP was carried out in triplicate and the assays were repeated three times. 


\section{Annexin-V and PI staining assay}

HCC cells were seeded in 6-well plates $\left(2 \times 10^{5}\right.$ per well $)$ and incubated with various concentrations of gefitinib in the presence or absence of DCP for $24 \mathrm{~h}$. Cells were harvested and washed with cold PBS. Levels of phosphatidylserine on the cell surface were quantitatively estimated using Annexin V-fluorescein isothiocyanate (FITC) and a propidium iodide (PI) apoptosis detection kit according to manufacturer's instructions (Becton Dickinson, USA). The apoptotic cells were detected using a Becton Dickinson FACScan cytofluorometer. Both early apoptotic (Annexin V-positive, PI-negative) and late apoptotic (Annexin V-positive and PI-positive) cells were included in cell apoptosis determinations [9]. The assay was carried out three times.

\section{Western blotting assay}

HCC cells were seeded in 6-well plates $\left(2-5 \times 10^{5}\right.$ per well) and incubated with gefitinib in the presence or absence of DCP for $24 \mathrm{~h}$. Cells were lysed in buffer containing $50 \mathrm{mmol} / \mathrm{L} \mathrm{HEPES} \mathrm{(pH} \mathrm{7.4),} 150 \mathrm{mmol} / \mathrm{L}$ $\mathrm{NaCl}, 0.1 \%$ Triton X-100, $1.5 \mathrm{mmol} / \mathrm{L} \mathrm{MgCl}_{2}, 1 \mathrm{mmol} / \mathrm{L}$ EDTA, $2 \mathrm{mmol} / \mathrm{L}$ sodium orthovanadate, $4 \mathrm{mmol} / \mathrm{L}$ sodium pyrophosphate, $100 \mathrm{mmol} / \mathrm{L} \mathrm{NaF}$, and a 1:500 protease inhibitor mixture (Sigma-Aldrich). Equal amounts of proteins were separated by $10 \%$ SDS-PAGE and then electro-transferred onto nitrocellulose, blocked with $5 \%$ nonfat dry milk for $1 \mathrm{~h}$ at room temperature, and then incubated with primary antibodies overnight. Appropriate horseradish peroxidase-conjugated secondary antibodies were added to Trisbuffered saline (TBS) containing 5\% nonfat milk. The bound antibodies were visualized using an enhanced chemiluminescence reagent (Millipore), and quantified by densitometry using a ChemiDoc XRS+ image analyzer (Bio-Rad, USA). The relative density of the protein was normalized to $\beta$-actin. The percentages of increase or decrease were estimated by comparison with the vehicle control (100\%) [10]. The primary antibodies included cleaved caspase-9 (Asp330) antibody (9501), cleaved caspase-3 (Asp175) antibody (9664), cleaved poly ADP-ribose polymerase (PARP, Asp214) antibody (9541), Bcl-2 antibody (2872), Bax antibody (2772), phospho-EGF receptor (Tyr998) antibody (2641), phospho-Met (Tyr1234/1235) antibody (3129) (Cell Signaling, USA), hepatocyte growth factor (HGF) antibody (sc-13087) (Santa Cruz, USA) and anti-beta actin antibody (ab6276, Abcam, USA).

\section{Statistical analysis}

Data are presented as the means \pm S.D and were analyzed by one-way ANOVA. Multiple betweengroup comparisons were performed using the S-N-K method. A $P$ value $<0.05$ was considered statistically significant. Statistical analysis was performed using SPSS/Win13.0 software (SPSS, Inc., Chicago, Illinois).

\section{Results}

\section{DCP antagonized the effect of gefitinib on HCC growth}

To determine the effect of gefitinib or DCP on HCC growth, PLC/PRF/5 or HepG2 cells were exposed to different concentrations of gefitinib or DCP for $72 \mathrm{~h}$. The profiles of cell proliferation were estimated by the MTT assay. As shown in Fig. 1A, 10, 20 and $30 \mu \mathrm{M}$ gefitinib inhibited the growth of PLC/PRF/5 by $25.6 \%, 46.8 \%$ and $69.6 \%$, respectively $(10$ $\mu \mathrm{M}, P<0.05 ; 20$ and $30 \mu \mathrm{M}, P<0.01 v s$. the vehicle control). The same concentrations of gefitinib that were used to treat PLC/PRF/5 cells inhibited cell growth of HepG2 cells by $37.4 \%, 50.6 \%$ and $71.6 \%$, respectively $(10 \mu \mathrm{M}, P<0.05 ; 20$ and $30 \mu \mathrm{M}, P<0.01 v$ s. the vehicle control).

Then, we determined the activity of DCP in PLC/PRF/5 and HepG2 cells. DCP could weakly stimulate cell growth. As shown in Fig. 1B, treatment of PLC/PRF/5 cells with DCP 2, 10 and $50 \mathrm{mAu} / \mathrm{mL}$ for $72 \mathrm{~h}$ led to a dose-dependent increase in the relative cell number by $8.2 \%, 14.8 \%$ and $23.4 \%$, respectively $(2$ and $10 \mathrm{mAu} / \mathrm{mL}, P>0.05 ; 50 \mathrm{mAu} / \mathrm{mL}, P<0.05 \mathrm{vs}$. the vehicle control); HepG2 cell number increased by $6.8 \%, 12.5 \%$ and $26.4 \%$, respectively $(2$ and $10 \mathrm{mAu} / \mathrm{mL}, P>0.05 ; 50 \mathrm{mAu} / \mathrm{mL}, P<0.05 \mathrm{vs}$. the vehicle control).

In the presence of DCP, the activity of gefitinib in the suppression of HCC growth was significantly weaker than that of gefitinib alone. We used $50 \mathrm{mAu} / \mathrm{mL}$ of DCP together with different concentrations of gefitinib to treat HCC cells. As shown in Fig. 1C, 10 and $20 \mu \mathrm{M}$ 
Fig. 1. The effects of gefitinib (A), DCP (B) and gefitinib plus DCP (C) on the proliferation of HCC cells. PLC/PRF/ 5 or HepG2 cells were exposed to gefitinib (A, 10, 20 and $30 \mu \mathrm{M})$, DCP (B, 2, 10 and $50 \mathrm{mAu} / \mathrm{mL}$ ) and different concentrations of gefitinib plus DCP (C, $50 \mathrm{mAu} / \mathrm{mL}$ ) for $72 \mathrm{~h}$. Viable cells were evaluated by the MTT assay and denoted as a percent of the vehicle control. The bars indicate mean \pm S.D $(\mathrm{n}=6) .{ }^{*} P<0.05,{ }^{* *} P<0.01$ vs. the vehicle control.

gefitinib for $72 \mathrm{~h}$ did not significantly inhibit the growth of PLC/PRF/5 and HepG2 cells $(P>0.05$ vs. the vehicle control). A significant reduction of HCC was observed when the concentration of gefitinib reached $20 \mu \mathrm{M}(P<0.05 v s$. the vehicle control). Statistical analysis indicated that in the presence of DCP, 10, 20 and $30 \mu \mathrm{M}$ of gefitinib for $72 \mathrm{~h}$ resulted in the inhibition of PLC/PRF/5 growth by only $3.9 \%, 8.8 \%$ and $16.3 \%$, respectively $(10$ and $20 \mu \mathrm{M}, P>0.05 ; 30 \mu \mathrm{M}, P<0.05$ $v s$. the vehicle control), and inhibitions of HepG2 by only $3.5 \%, 12.5 \%$ and $22.3 \%$, respectively $(10$ and $20 \mu \mathrm{M}, P>0.05$; $30 \mu \mathrm{M}, P<0.05 v s$. the vehicle control). Significant differences were observed between gefitinib alone and concurrent use with DCP. These results suggested that DCP possesses activity against gefitinibinduced growth inhibition of HCC.

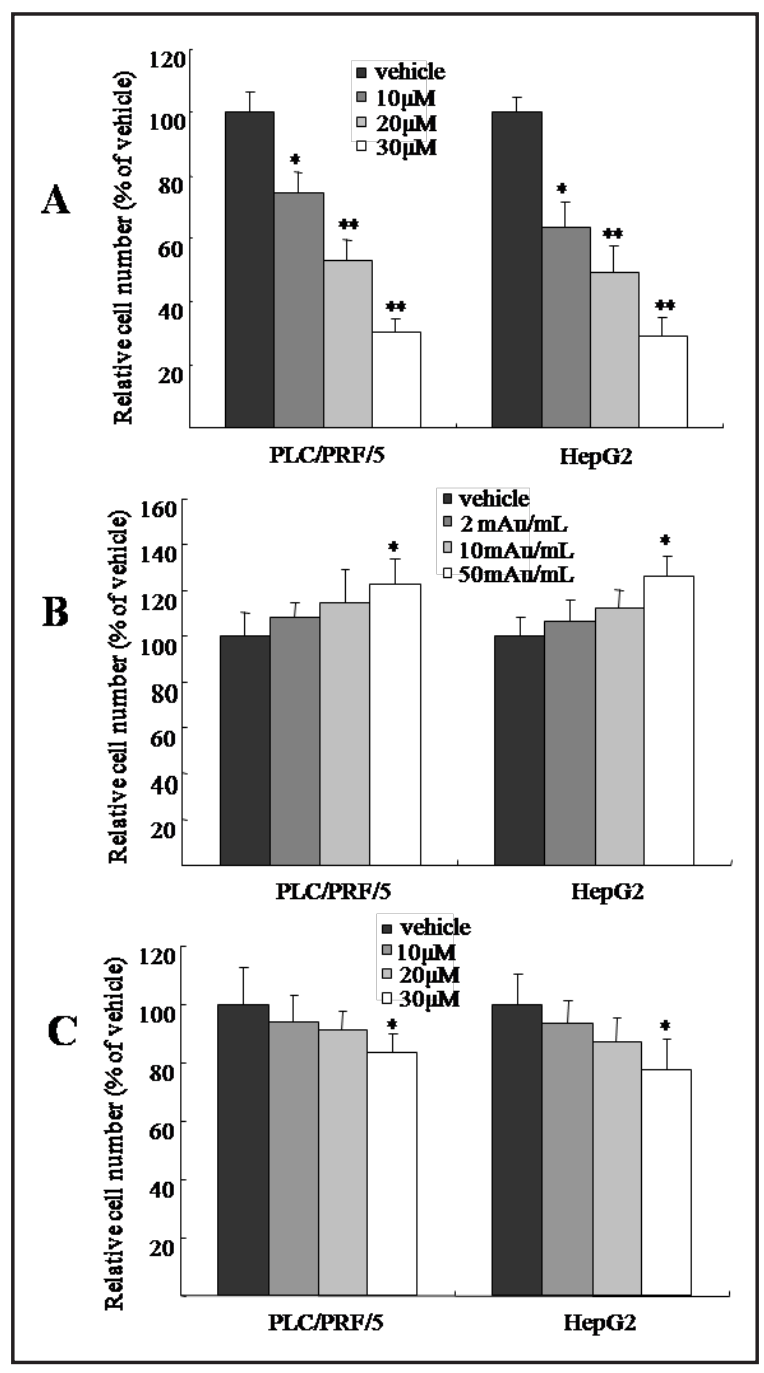

DCP prevented the gefitinib-induced apoptosis in HCC

Gefitinib was found to have the ability to induce apoptosis of HCC cells. PLC/PRF/5 and HepG2 cells were exposed to different concentrations of gefitinib for $24 \mathrm{~h}$ and then subjected to an Annexin-V and PI staining assay. Gefitinib significantly and dose-dependently induced the apoptosis of PLC/PRF/5 cells (Fig. 2A). In the presence of DCP, the effect of the gefitinibinduced apoptosis on HCC was antagonized. We selected a concentration of $30 \mu \mathrm{M}$ gefitinib together with different concentrations of DCP to treat HCC cells. In the absence of DCP, 30 $\mu \mathrm{M}$ gefitinib increased the population of apoptotic PLC/PRF/5 cells by $22.2 \%(P<0.01 \mathrm{vs}$. the vehicle control). However, in the presence of DCP, the percentage of gefitinib-induced apoptotic cells was significantly lower compared with cells treated with gefitinib alone. To further analyze the antagonistic effect of DCP on gefitinib, we used a constant concentration of gefitinib in combination with different concentrations of DCP to treat HCC. The ability of gefitinib to induce apoptosis was decreased as the concentrations of DCP were increased. As shown in Fig. $2 A^{\prime}$, the percentages of apoptotic cells induced by $30 \mu \mathrm{M}$ gefitinib were gradually decreased from $24.8 \%$ in the absence of DCP to $21.1 \%, 11.3 \%$ and $7.2 \%$, respectively, when cells were co-treated with gefitinib and DCP 2, 10 and $50 \mathrm{mAu} / \mathrm{mL}(2 \mathrm{mAu} / \mathrm{mL}, P>0.05$; 10 and $50 \mathrm{mAu} / \mathrm{mL}, P<0.01 \mathrm{vs}$. gefitinib alone). Statistical analysis revealed a significant difference between gefitinib alone and gefitinib plus DCP. These results suggested that DCP prevented the gefitinib-induced apoptosis of HCC cells. 


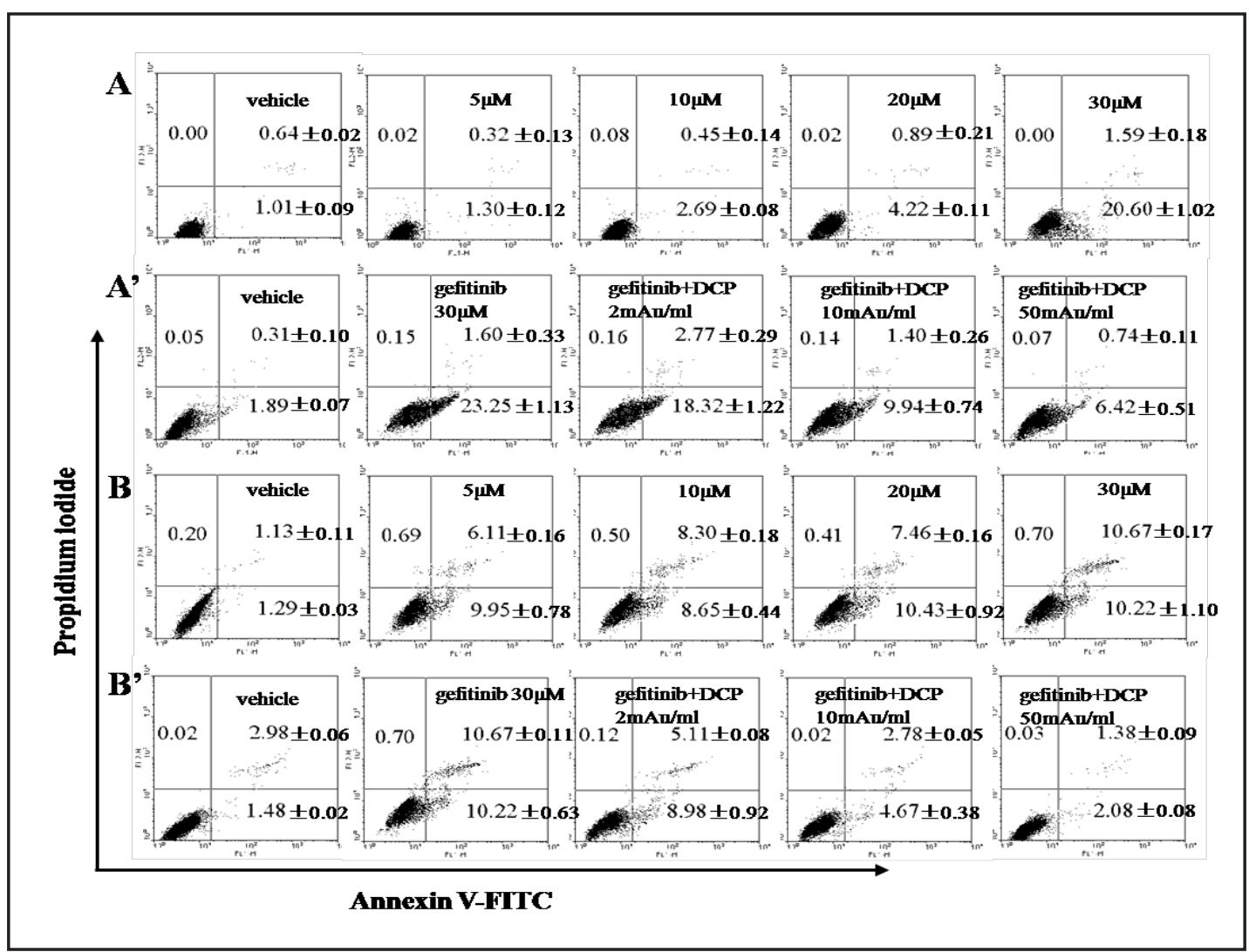

Fig. 2. The induction of apoptosis by gefitinib and the antagonistic effect of DCP on gefitinib in HCC. PLC/ PRF/ 5 or HepG2 cells were exposed to gefitinib alone or gefitinib plus DCP for $24 \mathrm{~h}$. Percentages of apoptotic cells were estimated by determining the levels of phosphatidylserine on the cell surface using an Annexin V-FITC and PI apoptosis detection kit. A: $30 \mu \mathrm{M}$ gefitinib alone in PLC/PRF/5 cells. A': $30 \mu \mathrm{M}$ gefitinib combined with different concentrations of DCP in PLC/PRF/5 cells. B: $30 \mu \mathrm{M}$ gefitinib alone in HepG2 cells. B': $30 \mu \mathrm{M}$ gefitinib combined with different concentrations of DCP in HepG2 cells. The bars indicate mean \pm S.D. $(n=3)$.

Similar profiles of the gefitinib-induced apoptosis of HCC cells and the antagonistic effect of DCP on gefitinib were also observed in HepG2 cells. As shown in Fig. 2B, gefitinib alone effectively induced the apoptosis of HepG2 cells. At gefitinib concentrations ranging from 5 to $30 \mu \mathrm{M}$ for $24 \mathrm{~h}$ exposure, the percentages of apoptotic cells were significantly increased by $16.1 \%, 17.0 \%, 17.9 \%$ and $20.9 \%$, respectively $(P<0.01 v$ s. the vehicle control). In the presence of DCP 2, 10 and $50 \mathrm{mAu} / \mathrm{mL}, 30 \mu \mathrm{M}$ gefitinib increased the population of apoptotic cells by only $14.1 \%, 7.4 \%$ and $3.4 \%$, respectively (Fig. $2 \mathrm{~B}^{\prime}, 2 \mathrm{mAu} / \mathrm{mL}, P<0.05 ; 10$ and $50 \mathrm{mAu} / \mathrm{mL}, P<0.01 \mathrm{vs}$. gefitinib alone).

DCP protected HCC cells from the gefitinib-induced apoptosis through preventing the activation of the caspase-dependent pathway

Western blotting analysis indicated that gefitinib could possibly induce the apoptosis of PLC/PRF/ 5 cells through activation of the caspase-dependent pathway. As shown in Fig. $3 \mathrm{~A}$, the levels of cleaved caspase- 9 were strongly increased by $35.1 \%, 86.1 \%$ and $206.3 \%$, respectively $(10 \mu \mathrm{M}, P<0.05 ; 20$ and $30 \mu \mathrm{M}, P<0.01 v s$. the vehicle control) in cells treated with gefitinib at concentrations of 10,20 and $30 \mu \mathrm{M}$ for $24 \mathrm{~h}$ exposure; cleaved caspase- 3 was increased by $21.3 \%, 76.8 \%$ and $196.7 \%$, respectively $(10 \mu \mathrm{M}, P<0.05,20$ and $30 \mu \mathrm{M}, P$ $<0.01$ vs. the vehicle control), and cleaved PARP by $35.1 \%, 63.2 \%$ and $185.7 \%$, respectively (10 and $20 \mu \mathrm{M}, P<0.05,30 \mu \mathrm{M}, P<0.01 v s$. the vehicle control). In the presence of DCP 50 $\mathrm{mAu} / \mathrm{mL}$, there was no apparent increase of these apoptotic proteins induced by gefitinib 
Zhang et al.: DCP Antagonized the Effect of Gefitinib on HCC

Table 1. The ratios of Bax/Bcl-2 in HCC cells after treatment with gefitinib and gefitinib plus DCP

\begin{tabular}{llcccc}
\hline Cell lines & Treatments & \multicolumn{1}{c}{ Vehicle } & \multicolumn{1}{c}{$10 \mu \mathrm{M}$} & \multicolumn{1}{c}{$20 \mu \mathrm{M}$} & \multicolumn{1}{c}{$30 \mu \mathrm{M}$} \\
\hline PLC/PRF/5 & gefitinib & $1.22 \pm 0.13$ & $1.81 \pm 0.14^{*}$ & $2.43 \pm 0.31^{* *}$ & $3.29 \pm 0.24^{* *}$ \\
& gefitinib + DCP & $1.37 \pm 0.31$ & $1.38 \pm 0.19$ & $1.47 \pm 0.63$ & $1.41 \pm 0.41$ \\
& & & & & \\
HepG2 & gefitinib & $1.29 \pm 0.23$ & $2.12 \pm 0.24^{*}$ & $2.64 \pm 0.43^{* *}$ & $3.3 \pm 0.26^{* *}$ \\
& gefitinib + DCP & $1.27 \pm 0.25$ & $1.16 \pm 0.29$ & $1.37 \pm 0.53$ & $1.41 \pm 0.67$ \\
\hline
\end{tabular}

compared with the vehicle control cells (Fig. 3A'). However, statistical analysis showed a significant difference between gefitinib alone and gefitinib plus DCP (Fig. $3 A$ and $A^{\prime}, P<0.01$ ). These results suggested that DCP might protect HCC cells from gefitinib-induced apoptosis by preventing the activation of the caspase-dependent pathway.

We examined the expression of Bax and Bcl-2 to further support these observations. Bax was activated and Bcl-2 was reduced in the gefitinib-treated cells (Fig. 3A and Table $1, P<0.05$ vs. the vehicle control). Consequently, the ratios of Bax/Bcl-2 were increased significantly. As shown in Table 1, the ratios of Bax/Bcl-2 in the gefitinib-treated PLC/PRF/5 cells were significantly increased from 1.22 in the vehicle control cells to $1.81,2.43$ and 3.29, respectively, by 10,20 and $30 \mu \mathrm{M}$ of gefitinib $(10 \mu \mathrm{M}, P<0.05 ; 20$ and $30 \mu \mathrm{M}, P<0.01$ vs. the vehicle control). Whereas, the increases of $\mathrm{Bax} / \mathrm{Bcl}-2$ ratios were not significant in the cells exposed to gefitinib plus DCP (Fig. 3A', Table 1, $P>0.01 v s$. the vehicle control). Significant differences existed between gefitinib alone and gefitinib plus DCP in their individual concentration (Table $1, P<0.05$ ).

Fig. 3B and Table 1 showed the similar alteration profiles of apoptotic proteins in HepG2 cells.

The expressions of Bax and Bcl-2 in PLC/PRF/5 and HepG2 cells were determined by Western blotting assay as described in the results. The ratios of Bax/Bcl-2 were calculated based on the percentage of increase of Bax or decrease of Bcl-2 compared with the vehicle control (100\%). ${ }^{*} P<0.05$ and ${ }^{* *} P<0.01$ vs. the vehicle control in PLC/PRF/5 or HepG2 cells. There were significant differences between gefitinib and gefitinib + DCP $(P<0.05)$.

The effects of c-Met, HGF and EGFR by gefitinib were antagonized by DCP

Previous studies indicated that gefitinib suppressed HCC growth through the suppression of EGFR pathway, whereas DCP was found to stimulate EGFR, c-Met and HGF in HCC. Based on these observations, we examined the levels of EGFR, c-Met and HGF in HCC cells exposed to gefitinib in the presence or absence of DCP. We initially determined the ability of DCP to stimulate the expression of these proteins in PLC/PRF/ 5 cells. As shown in Fig. 4, the levels of p-EGFR were strongly increased by $225.1 \%$, 294.8\% and $326.9 \%$ after treatment with DCP 2, 10 and $50 \mathrm{mAu} / \mathrm{mL}$, respectively, for $24 \mathrm{~h}(P<0.01 \mathrm{vs}$. the vehicle control); EGFR was increased by $75.7 \%, 126.8 \%$ and $204.6 \%$, respectively $(2 \mathrm{mAu} / \mathrm{mL}$, $P<0.05 ; 10$ and $50 \mathrm{mAu} / \mathrm{mL}, P<0.01$ vs. the vehicle control); p-c-Met by $29.5 \%, 60.8 \%$ and $74.7 \%$, respectively $(2 \mathrm{mAu} / \mathrm{mL}, P>0.05 ; 10$ and $50 \mathrm{mAu} / \mathrm{mL}, P<0.05$ vs. the vehicle control); HGF by $29.4 \%, 39.5 \%$ and $148.3 \%$, respectively ( 2 and $10 \mathrm{mAu} / \mathrm{mL}, P>0.05 ; 50$ $\mathrm{mAu} / \mathrm{mL}, P<0.01$ vs. the vehicle control).

We then determined the activity of gefitinib in the inhibition of these proteins in HCC cells. Gefitinib effectively inhibited the expression of EGFR, c-Met and HGF in PLC/PRF/5 cells. As shown in Fig. 5A, 10, 20 and $30 \mu \mathrm{M}$ gefitinib significantly reduced the levels of p-EGFR by $54.3 \%, 78.4 \%$ and $91.3 \%$, respectively $(P<0.01$ vs. the vehicle control); EGFR was reduced by $45.5 \%, 59.9 \%$, and $89.8 \%$, respectively $(10 \mu \mathrm{M}, P<0.05 ; 20 \mu \mathrm{M}$ and $30 \mu \mathrm{M}$, $P<0.01$ vs. the vehicle control); p-c-Met by $81.6 \%, 86.4 \%$ and $91.6 \%$, respectively $(P<0.01$ $v s$. the vehicle control); HGF by $48.6 \%, 55.8 \%$ and $64.9 \%$, respectively $(10 \mu \mathrm{M}, P<0.05 ; 20$ $\mu \mathrm{M}$ and $30 \mu \mathrm{M}, P<0.01 v s$. the vehicle control).

In the presence of DCP, the effects of gefitinib-induced suppression of these proteins were significantly lower than that of the cells without exposure to DCP. Fig. $5 A^{\prime}$ showed the 


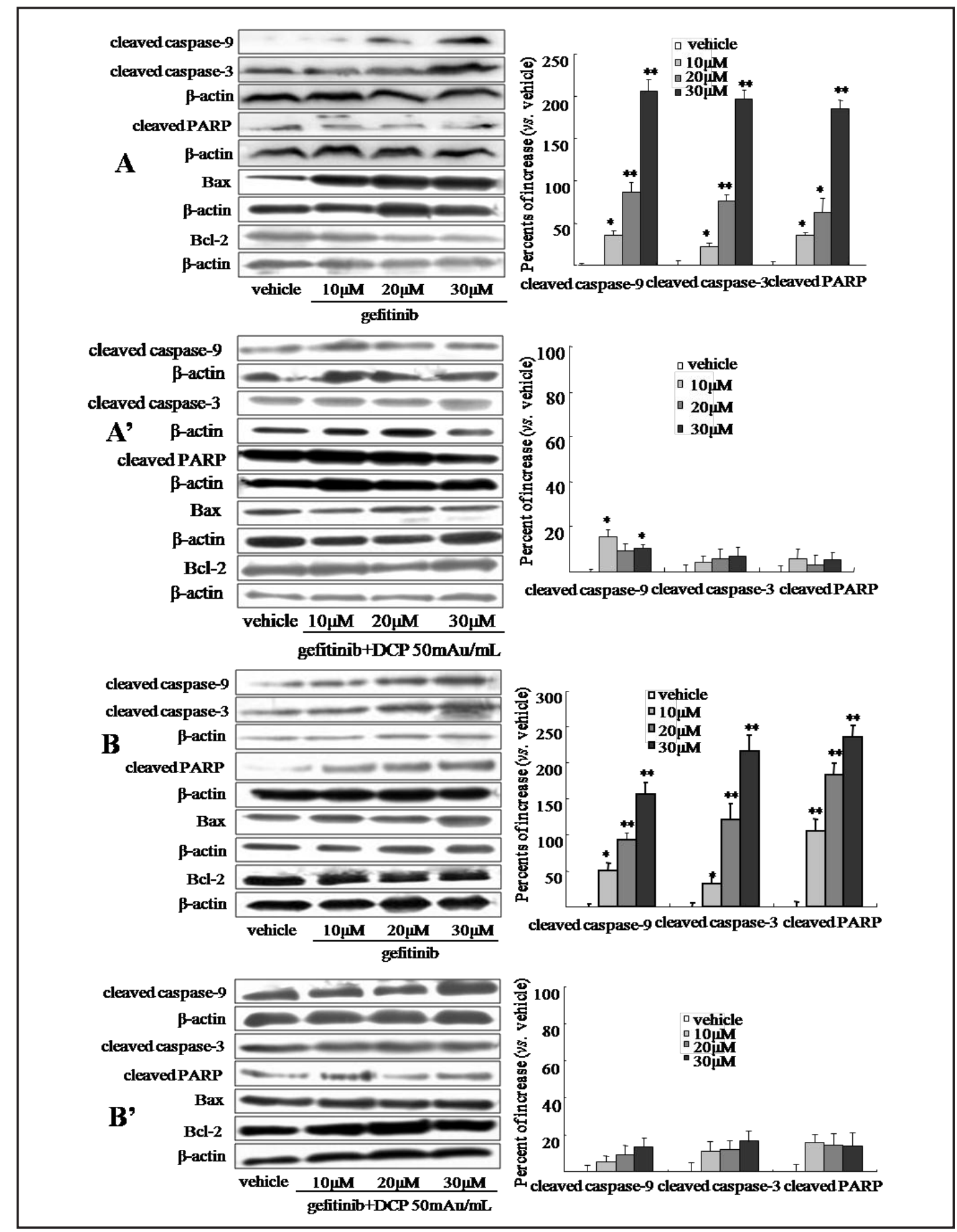

Fig. 3. A Western blotting assay was used to detect the levels of proteins related to the apoptotic caspasedependent pathway in PLC/PRF/5 (A) and HepG2 (B) cells. HCC cells seeded in 6-well plates were exposed to gefitinib in the presence or absence of DCP for $24 \mathrm{~h}$. The levels of cleaved caspase-9, cleaved caspase-3, cleaved PARP, Bax and Bcl-2 were determined using a Western blotting assay. The relative density of the protein was normalized to $\beta$-actin. The percentages of increase or decrease of protein levels were estimated by comparison with the vehicle control (100\%). A: Gefitinib alone in PLC/PRF/5 cells. A': Various concentrations of gefitinib plus $50 \mathrm{mAu} / \mathrm{mL}$ DCP in PLC/PRF/5 cells. B: Gefitinib alone in HepG2 cells. B': Various concentrations of gefitinib plus DCP $50 \mathrm{mAu} / \mathrm{mL}$ in HepG2 cells. The bars indicate mean \pm S.D. $(\mathrm{n}=3)$. ${ }^{*} P<$ $0.05,{ }^{* *} P<0.01$ vs. the vehicle control.

\section{KARGER}


Fig. 4. A Western blotting assay was used to determine the expressions of p-EGFR, EGFR, p-c-Met and HGF in PLC/PRF/ 5 cells exposed to DCP. The relative densities of the proteins were normalized to $\beta$-actin. The increases of these proteins were estimated by comparison to the vehicle control $(100 \%)$. The bars indicate mean \pm S.D $(\mathrm{n}=3) .{ }^{*} P<0.05,{ }^{* *} P<0.01$ vs. the vehicle control.

alterations of EGFR, c-Met and HGF in PLC/ PRF/5 cells exposed to gefitinib plus DCP. Gefitinib at concentrations of 10,20 and 30 $\mu \mathrm{M}$ plus DCP $50 \mathrm{mAu} / \mathrm{mL}$ resulted in the inhibitions of p-EGFR by only $22.6 \%, 26.8 \%$ and $24.5 \%$, respectively $(30 \mu \mathrm{M}, P<0.05 v s$. the vehicle control); EGFR by only $14.7 \%$, $20.4 \%$ and $35.9 \%$, respectively $(30 \mu \mathrm{M}, P$ $<0.05$ vs. the vehicle control); p-c-Met by only $36.7 \%, 30.4 \%$ and $24.6 \%$, respectively $(10 \mu \mathrm{M}, P<0.05 ; 20 \mu \mathrm{M}$ and $30 \mu \mathrm{M}, P>0.05$ vs. the vehicle control); HGF by only $25.9 \%$,

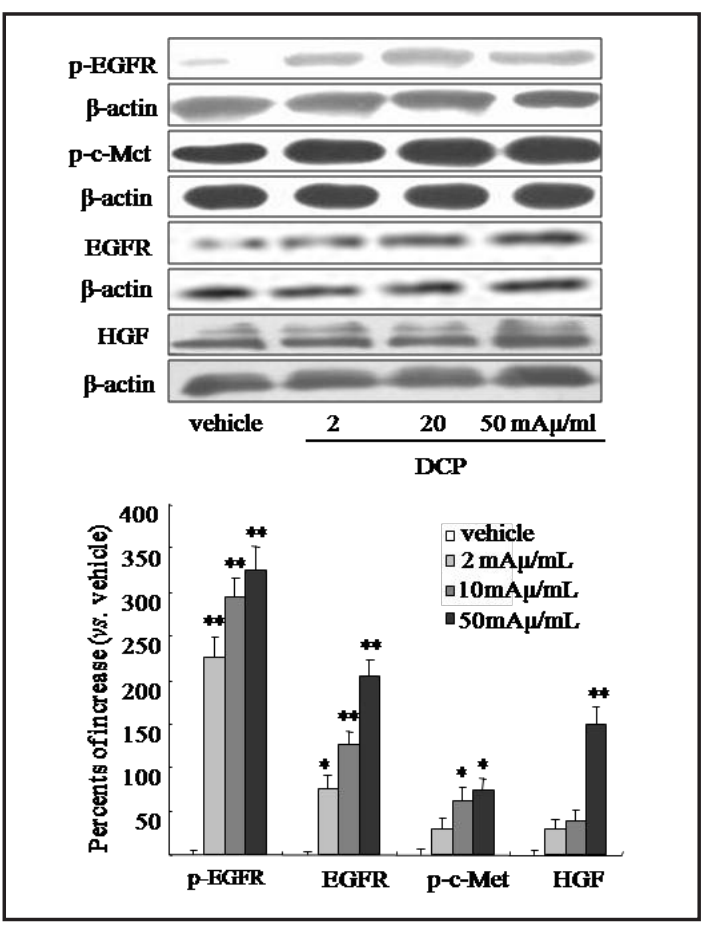
$29.3 \%$ and $26.1 \%$, respectively ( $P>0.05$ vs. the vehicle control). Significant differences existed between gefitinib alone and gefitinib plus DCP (Fig. 5A and A', $P<0.05$ ). These results suggested that DCP antagonizes the effects of gefitinib on HCC through the up-regulation of the EGFR pathway.

The effects of DCP on the gefitinib-induced suppression of EGFR pathway were mirrored in HepG2 cells (Fig. 5B and B').

\section{Discussion}

DCP is a prothrombin precursor produced in HCC $[11,12]$. Since Liebman et al. described elevated plasma DCP in patients with HCC, DCP has been used as a marker for diagnosis of HCC [13]. Clinical reports indicated that the levels of plasma DCP were frequently elevated in 63\% of patients with HCC [14-16]. High levels of DCP are considered to be associated with large tumor sizes and recurrences of HCC [17]. Tumor recurrences and metastases are more frequent in patients with positive DCP than in patients with negative DCP [18, 19]. Therefore, DCP has been used as a marker for diagnosis of HCC and also used for monitoring treatment responsiveness and tumor recurrence. The level of DCP in plasma is usually determined by the enzyme immunoassay. The cut-off serum DCP level is $40 \mathrm{mAU} /$ $\mathrm{ml}[20]$. According to recent reports, this level of DCP could sensitize $81-98 \%$ of HCC < $3 \mathrm{~cm}$ in diameter [21]. Therefore, serum DCP $40 \mathrm{mAU} / \mathrm{ml}$ has been considered to be the high level [22]. However, the clinical significance of DCP production has remained poorly understood. Recently, its biological malignant potential in HCC has been reported by our group and many other investigators. In these reports, DCP was described as an autologous growth factor to stimulate HCC growth and a paracrine interaction factor between HCC and vascular endothelial cells to increase angiogenesis [23-27].

It is well known that HCC is less sensitive to most chemotherapeutic agents than many other tumors [28]. Thus, it is essential to investigate the underlying mechanisms of HCC resistance to drug treatment and explore a potential strategy to enhance the efficacy of chemotherapeutic agents. Recently, the association of DCP production and drug treatment failure has received much attention. Gefitinib, a tyrosine kinase inhibitor, has been described to have survival benefits for patients with advanced HCC [29]. However, the efficacy of 


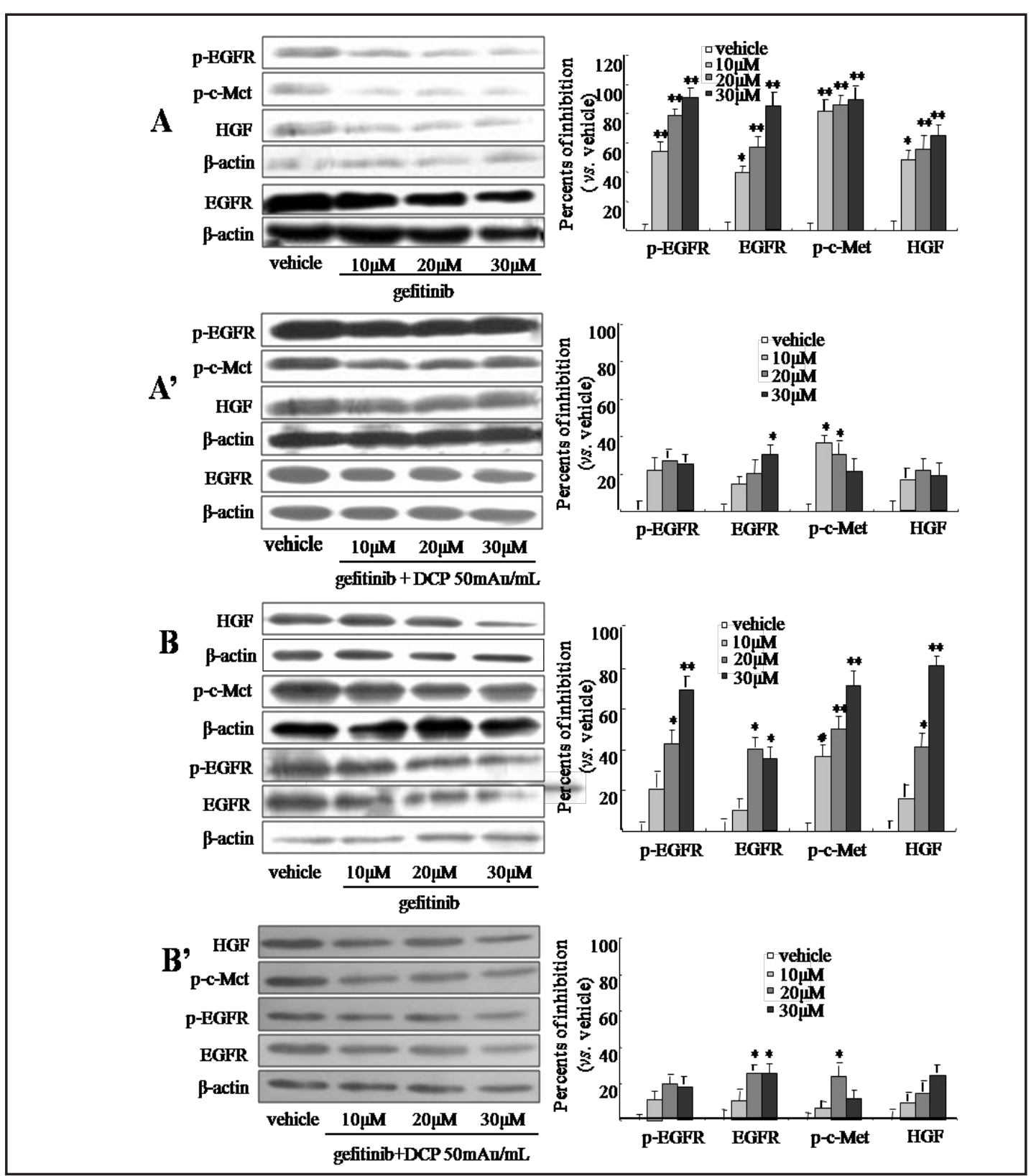

Fig. 5. A Western blotting assay was used to determine the expressions of p-EGFR, EGFR, p-c-Met and HGF in HCC cells exposed to gefitinib, DCP or gefitinib plus DCP. The expression of p-EGFR, EGFR, p-c-Met and HGF was detected by Western blotting. The relative densities of the proteins were normalized to $\beta$-actin. The percentages of inhibition were estimated by comparison with the vehicle control (100\%). A: Gefitinib reduced levels of p-EGFR, EGFR, p-c-Met and HGF in PLC/PRF/5 cells. A': The inhibitory effect of gefitinib on HCC was significantly antagonized by DCP in PLC/PRF/5 cells. B: Gefitinib alone in HepG2 cells. B': Gefitinib plus DCP in HepG2 cells. The bars indicate mean \pm S.D $(n=3) .{ }^{*} P<0.05,{ }^{* *} P<0.01$ vs. the vehicle control.

gefitinib treatment is quite variable [30]. In some patients, treatment with gefitinib had limited benefits with low response rates or no response to gefitinib [7]. We hypothesized that high levels of DCP in the serum might be associated with gefitinib treatment failure or lower efficacy in HCC. In fact, this association has been observed in many HCC cases after treatment with gefitinib and many other tyrosine kinase inhibitors [31]. The accumulating evidence revealed that the efficacy of sorafenib, also a tyrosine kinase inhibitor, is usually low 
in patients with high serum DCP [32-34]. For example, in a study by Kuzuya and colleagues, it was suggested that high levels of serum DCP indicate treatment failure by tyrosine kinase inhibitor [33]. In the current study, we mimicked the microenvironment of HCC by using DCP $2-50 \mathrm{mAU} / \mathrm{ml}$ and then treated the cells with gefitinib. DCP was found to antagonize the effect of gefitinib on the inhibition of HCC growth. We therefore suggested that high levels of DCP might prevent the gefitinib-induced inhibition of HCC growth. DCP production could possibly be one of the reasons for treatment failure with gefitinib. In the experiments described herein, we established the association of DCP with the efficacy of gefitinib in HCC. Gefitinib effectively inhibited HCC growth. On the contrary, DCP stimulated HCC growth. In the presence of DCP, the gefitinib-induced growth inhibition of HCC was significantly lower than that of the cells exposed to gefitinib alone. These observations were further demonstrated at the molecular level by a Western blotting assay. The suppression of EGFR, c-Met and HGF by gefitinib were obviously attenuated when HCCs were concurrently exposed to DCP. We therefore suggested that the activity of DCP against the gefitinib-induced growth inhibition of HCC was mediated through its ability to up-regulate the EGFR pathway.

Many reports indicated that the gefitinib-induced growth inhibition of cancers was mainly due to its effects on apoptotic induction [35, 36]. Hence, we investigated whether DCP could protect HCC cells from gefitinib-induced apoptosis. Our results demonstrated that gefitinib could induce the apoptosis of HCC cells through the activation of the apoptotic caspase-dependent pathway. In this pathway, the activation of caspase molecules and their substrates is the central apoptotic event [37]. The externalization of phosphatidylserine, a phospholipid normally restricted to the inner leaflet of plasma membrane, is one of the earliest apoptotic events [38]. We therefore evaluated the efficacy of gefitinib by determining the levels of phosphatidylserine. Further studies indicated that gefitinib effectively induced the activation of cleaved caspase-9, cleaved caspase-3 and cleavage of PARP, which were strictly controlled by the activation of the Bcl-2 family as indicated by the Bax/Bcl-2 ratio $[37,39,40]$. We thus determined the levels of these molecules to be related to the apoptotic caspase-dependent pathway. In the presence of DCP, the efficacy of the gefitinib-induced activation of these caspase molecules was significantly lower compared with gefitinib alone. DCP also possessed activity against the gefitinib-induced activation of Bax and suppression of Bcl-2. These results indicated that DCP antagonized gefitinib-induced apoptosis in HCC. DCP might prevent gefitinib-induced apoptosis in HCC through inhibiting the activation of the caspase-dependent pathway. We suggested that the product of DCP in HCC cells might be one of the reasons for lower efficacy and poorer response to gefitinib in HCC patients. High serum DCP might indicate treatment failure with gefitinib. Thus, DCP continues to be used as a diagnostic marker, and DCP is also a promising target for development of HCC chemotherapy. Development of DCP inhibitors and their use might improve the efficacy of gefitinib and many other tyrosine kinase inhibitors for the treatment of HCC [20,41].

Conclusions: This study provides evidence that DCP antagonizes gefitinib-induced growth inhibition of HCC. DCP might exert its antagonistic effects on gefitinib through anti-apoptotic mechanisms and the up-regulation of the EGFR pathway. Further work in additional cell lines to explore the in depth mechanism are currently underway.

\section{Disclosure Statement}

We confirm that there is no conflict of interest or financial dependence regarding this paper.

\section{Acknowledgements}

This work was supported by a grant from Natural Science Foundation of China (81173090). We are genuinely thankful to Dr. Wei Tang at Graduate School of Medicine, University of Tokyo for his help with the funding application. 
Zhang et al.: DCP Antagonized the Effect of Gefitinib on HCC

\section{References}

1 Thomas MB: Systemic therapy for hepatocellular carcinoma. Cancer J 2008;14:123-127.

2 Llovet JM, Hernandez-Gea V: Hepatocellular carcinoma: reasons for phase III failure and novel perspectives on trial design. Clin Cancer Res 2014;20:2072-2079.

-3 Gao ZH, Tretiakova MS, Liu WH, Gong C, Farris PD, Hart J: Association of Ecadherin, matrix metalloproteinases, and tissue inhibitors of metalloproteinases with the progression and metastasis of hepatocellular carcinoma. Mod Pathol 2006;19:533-540.

-4 Bodzin AS, Wei Z, Hurtt R, Gut T, Doria C: Gefitinib resistance in HCC mahlavu cells: upregulation of CD133 expression, activation of IGF-1R signaling pathway, and enhancement of IGF-1R nuclear translocation. J Cell Physiol 2012;227:2947-2952.

-5 Fung AS, Yu M, Ye QJ, Tannock IF: Scheduling of paclitaxel and gefinib to inhibit repopulation for optimal treatment of human cancer cells and xenografts that overexpress the epidermal growth factor receptor. Cancer Chemother Pharmacol 2013;72:585-595.

6 Nakagawa T, Takeuchi S, Yamada T, Nanjo S, Ishikawa D, Sano T, Kita K, Nakamura T, Matsumoto K, Suda K, Mitsudomi T, Sekido Y, Uenaka T, Tano S: Combined therapy with mutant-selective EGFR inhibitor and Met kinase inhibitor for overcoming erlotinib resistance in EGFR-mutant lung cancer. Mol Cancer Ther 2012;11:2149-2157.

7 Rossi L, Zoratto F, Papa A, Iodice F, Minozzi M, Frati L, Tomao S: Current approach in the treatment of hepatocellular carcinoma. World J Gastrointest Oncol 2010;2:348-359.

8 Wang SB, Cheng YN, Cui SX, Zhong JL, Ward SG, Sun LR, Chen MH, Kokudo N, Tang W, Qu XJ: Des-gammacarboxy prothrombin stimulates human vascular endothelial cell growth and migration. Clin Exp Metastasis 2009;26:469-477. Qin Y, Lu Y, Wang R, Li W, Qu X. SL1122-37, a novel derivative of sorafenib, has greater effects than sorafenib on the inhibition of human hepatocellular carcinoma (HCC) growth and prevention of angiogenesis. Biosci Trends 2013;7:237-244.

10 Gong C, Xu C, Ji L, Wang Z: A novel semi-synthetic andrographolide analogue A5 inhibits tumor angiogenesis via blocking the VEGFR2-p38/ERK1/2 signal pathway. Biosci Trends 2013;7:230-236.

11 Chen KF, Chen HL, Tai WT, Feng WC, Hsu CH, Chen PJ, Cheng AL: Activation of phosphatidylinositol 3-kinase/Akt signaling pathway mediates acquired resistance to sorafenib in hepatocellular carcinoma cells. J Pharmacol Exp Ther 2011;337:155-161.

12 Zhai B, Sun XY: Mechanisms of resistance to sorafenib and the corresponding strategies in hepatocellular carcinoma. World J Hepatol 2013;5:345-352.

13 Liebman HA: Isolation and characterization of a hepatomaassociated abnormal (des-gamma-carboxy) prothrombin. Cancer Res 1989;49:6493-6497.

-14 Yue P, Gao ZH, Xue X, Cui SX, Zhao CE, Yuan Y, Yin Z, Inagaki Y, Kokudo N, Tang W, Qu XJ: Des- $\gamma$-carboxyl prothrombin induces matrix metalloproteinase activity in hepatocellular carcinoma cells by involving the ERK1/2 MAPK signaling pathway. Eur J Cancer 2011;47:1115-1124.

15 Weitz IC, Liebman HA: Des-gamma-carboxy (abnormal) prothrombin and hepatocellular carcinoma: a critical review. Hepatology 1993;18:990-997.

16 Tameda M, Shiraki K, Sugimoto K, Ogura S, Inagaki Y, Yamamoto N, Ikejiri M, Takei Y, Ito M, Nobori T: Des- $\gamma$ carboxy prothrombin ratio measured by P-11 and P-16 antibodies is a novel biomarker for hepatocellular carcinoma. Cancer Sci 2013;104:725-731.

17 Song P, Gao J, Inagaki Y, Kokudo N, Hasegawa K, Sugawara Y, Tang W: Biomarkers: evaluation of screening for and early diagnosis of hepatocellular carcinoma in Japan and China. Liver Cancer 2013;2:31-39.

-18 Shimada M, Yamashita Y, Hamatsu T, Hasegawa H, Utsunomiya T, Aishima S, Sugimachi K: The role of des-gamma-carboxy prothrombin levels in hepatocellular carcinoma and liver tissues. Cancer Lett 2000;159:87-94.

19 Yuen MF, Lai CL: Serological markers of liver cancer. Best Pract Res Clin Gastroenterol 2005;19:91-99.

20 Inagaki Y, Tang W, Makuuchi M, Hasegawa K, Sugawara Y, Kokudo N: Clinical and molecular insights into the hepatocellular carcinoma tumour marker des- $\gamma$-carboxyprothrombin. Liver Int 2011;31:22-35.

21 Fujikawa T, Shiraha H, Yamamoto K: Significance of des-gamma-carboxy prothrombin production in hepatocellular carcinoma. Acta Med Okayama 2009;63:299-304.

22 Saito M, Seo Y, Yano Y, Miki A, Yoshida M, Azuma T: A high value of serum des- $\gamma$-carboxy prothrombin before hepatocellular carcinoma treatment can be associated with long-term liver dysfunction after 
treatment. J Gastroenterol 2012;47:1134-1142.

23 Ma M, Qu XJ, Mu GY, Chen MH, Cheng YN, Kokudo N, Tang W, Cui SX: Vitamin K2 inhibits the growth of hepatocellular carcinoma via decrease of des-gamma-carboxy prothrombin. Chemotherapy 2009;55:28-35.

24 Gao FJ, Cui SX, Chen MH, Cheng YN, Sun LR, Ward SG, Kokudo N, Tang W, Qu XJ: Des- $\gamma$-carboxyl prothrombin increases the expression of angiogenic factors in human hepatocellular carcinoma cells. Life Sci 2008;83:815-820.

25 Suzuki M, Shiraha H, Fujikawa T, Takaoka N, Ueda N, Nakanishi Y, Koike K, Takaki A, Shiratori Y: Des- $\gamma$ carboxyl prothrombin is a potential autoloous growth factor for hepatocellular carcinoma. J Biol Chem 2005;280:6409-6415.

26 Fujikawa T, Shiraha H, Ueda N, Takaoka N, Nakanishi Y, Matsuo N, Tanaka S, Nishina S, Suzuki M, Takaki A, Sakaguchi K, Shiratori Y: Des- $\gamma$-carboxyl prothrombin-promoted vascular endothelial cell proliferation and migration. J Biol Chem 2007;282:8741-8748.

27 Ueda N, Shiraha H, Fujikawa T, Takaoka N, Nakanishi Y, Suzuki M, Matsuo N, Tanaka S, Nishina S, Uemura M, Takaki A, Shiratori Y, Yamamoto K: Exon 2 deletion splice variant of gamma-glutamyl carboxylase causes des-gamma-carboxy prothrombin production in hepatocellular carcinoma cell lines. Mol Oncol 2008;2:241-249.

-28 Crissien AM, Frenette C: Current management of hepatocellular carcinoma. Gastroenterol Hepatol (N Y). 2014;10:153-161.

29 Bodzin AS, Wei Z, Hurtt R, Gu T, Doria C: Gefitinib resistance in HCC mahlavu cells: upregulation of CD133 repression, activation of IGF-1R signaling pathway, and enhancement of IGF-1R nuclear translocation. J Cell Physiol 2012;227:2947-2952.

-30 Losert A, Lötsch D, Lackner A, Koppensteiner H, Peter-Vörösmarty B, Steiner E, Holzmann K, Grunt T, Schmid K, Marian B, Grasl-Kraupp B, Schulte-Hermann R, Krupitza G, Berger W, Grusch M: The major vault protein mediates resistance to epidermal growth factor receptor inhibition in human hepatoma cells. Cancer Lett 2012;319:164-172.

- 31 Inagaki Y, Qi F, Gao J, Qu X, Hasegawa K, Sugawara Y, Tang W, Kokudo N: Effect of c-Met inhibitor SU11274 on hepatocellular carcinoma cell growth. Biosci Treads 2011;5:52-56.

-32 Miyahara K, Nouso K, Morimoto Y, Tomoda T, Kobayashi S, Takeuchi Y, Hagihara H, Kuwaki K, Ohnishi H, Ikeda F, Miyake Y, Nakamura S, Shiraha H, Takaki A, Yamamoto K: Evaluation of the effect of sorafenib using serum NX-des- $\gamma$-carboxyprothrombin in patients with hepatocellular carcinoma. Hepatol Res 2013;43:1064-1070.

33 Kuzuya T, Asahina Y, Tsuchiya K, Tanaka K, Suzuki Y, Hoshioka T, Tamaki S, Kato T, Yasui Y, Hosokawa T, Ueda K, Nakanishi H, Itakura J, Takahashi Y, Kurosaki M, Izumi N: Early decrease in $\alpha$-fetoprotein, but not des- $\gamma$-carboxy prothrombin, predicts sorafenib efficacy in patients with advanced gepatocellular carcinoma. Oncology 2011;81:251-258.

-34 Ueshima K, Kudo M, Takita M, Nagai T, Tatsumi C, Ueda T, Kitai S, Ishikawa E, Yada N, Inoue T, Hagiwara S, Minami Y, Chung H, Sakurai T: Des- $\gamma$-carboxy prothrombin may be a promising biomarker to determine the therapeutic efficacy of sorafenib for hepatocellular carcinoma. Dig Dis 2011;29:321-325.

-35 Breunig C, Mueller BJ, Umansky L, Wahi K, Hoffmann K, Lehner F, Manns MP, Bantel H, Falk CS: B-Raf and MEK inhibitors differentially regulate cell fate and microenvironment in human hepatocellular carcinoma. Clin Cancer Res 2014;20;2410-2423.

-36 Meyer A, Cygan P, Tolzien K, Galvez AG, Bitran JD, Lestingi TM, Nabhan C: Role of sorafenib in overcoming resistance of chemotherapy-failure castration-resistant prostatecancer. Clin Genitourin Cancer 2014;12:100-105.

-37 Yue B, Zhang YS, Xu HM, Zhao CR, Li YY, Qin YZ, Wang RQ, Sun D, Yuan Y, Lou HX, Qu XJ: Riccardin D-26, a synthesized macrocyclic bisbibenzyl compound, inhibits human hepatocellular carcinoma growth through induction of apoptosis in p53-dependent way. Cancer Let 2013;328:104-113.

- 38 George SE, Anderson RJ, Haswell M, Grpundwater PW: An investigation of the effects of dithranol-induced apoptosis in a human keratinocyte cell line. J Pharm Pharmacol 2013;65:552-560.

-39 Li H, Zhou S, Li X, Wang D, Wang Y, Zhou C, Schmid-Bindert G: Gefitinib-resistance is related to BIM expression in non-small cell lung cancer cell lines. Cancer Biother Radiopharm 2013;28:115-123.

40 Chu JH, Zhao CR, Song ZY, Wang RQ Qin YZ, Li WB, Qu XJ: 1082-39, an analogue of sorafenib, inhibited human cancer cell growth more potently than sorafenib. Biomed Pharmacother 2014;68:335-341.

-41 Zhang YS, Chu JH, Cui SX, Song ZY, Qu XJ. Des- $\gamma$-carboxy prothrombin (DCP) as a potential autologous growth factor for the development of hepatocellular carcinoma. Cell Physiol Biochem 2014;34:903-915. 


\section{Erratum}

In the article by Zhang et al., entitled "Des-gamma-carboxy prothrombin (DCP) antagonizes the effects of gefitinib on human hepatocellular carcinoma cells " [Cell Physiol Biochem 2015;35:201-212 (DOI: 10.1159/000369688)], is a printing error in the affiliations and authors order.

The corrected authors order and their affiliations are stated correctly here:

Shu-Xiang Cui ${ }^{\mathrm{a}}$ Yu-Sheng Zhang ${ }^{\mathrm{b}}$ Jia-Hui Chu ${ }^{\mathrm{b}}$ Zhi-Yu Song ${ }^{\mathrm{b}} \quad$ Xian-Jun $\mathrm{Qu}^{\mathrm{c}}$

${ }^{a}$ Evaluation Center for Food and Drug, Capital Medical University, Beijing, ${ }^{b}$ School of Pharmaceutical Sciences, Shandong University, Jinan, 'Department of Pharmacology, Capital Medical University School of Basic Medical Sciences, Beijing, China 